\title{
THE DISTRIBUTION OF ENERGY IN THE SPECTRUM OF THE GLOW-LAMP.
}

\author{
(PRELIMINARY MEASUREMENTS.)
}

By EdWARd L. Nichols.

I.

$\mathrm{T}$ HE glow-lamp affords an interesting subject of study. In the first place, it is possible by varying the current in the filament to secure a very wide range in the temperature of the radiating surface, extending upwards to temperatures considerably higher than those of ordinary luminous gas flames, and to maintain more constant the condition of incandescence during the progress of each set of measurements than is possible in the case of any other source of light. In the second place, the study of the spectrum of the incandescent lamp affords an answer to certain questions of considerable practical importance.

In. 1885, Messrs. Siemens and Halske, of Berlin published the results of measurements for the purpose of showing the superiority of the silver-gray surface obtained by treating filaments of glowlamps by bringing the same to incandescence in an atmosphere consisting of volatile hydro-carbon. In the following year Mr. Mortimer Evans ${ }^{1}$ described comparisons of the radiation from bright and black incandescent lamp filaments in which the superiority of the former was very clearly demonstrated. Evans selected two filaments of similar size and structure, one of which he subjected to a surface deposition obtained by. flashing in an atmosphere of ordinary coal gas; the result being a hard coating of carbon of the color of lampblack. The other filament was flashed in an atmosphere of volatilized hydro-carbons, by which means the usual silver-gray surface was obtained. The two fila-

${ }^{1}$ Evans, Proceedings of the Royal Society, Feb. 18, 1886. 
ments were then mounted and exhausted to the ten-thousandth of an atmosphere, and characteristic curves were made, showing, (I) the relationship between the efficiency of the lamps, expressed in watts per candle, and candle power (see Fig. I); (2) the relation between the total watts consumed in each lamp and the candle power. These curves show a very much greater amount of light for the energy expended in the case of the filament with bright surface.

Subsequently, two filaments of close firm structure and of equal size were obtained which possessed the usual dull, dead black color resulting from carbonization without treatment. The characteristic curve of one of these was obtained after mounting the same

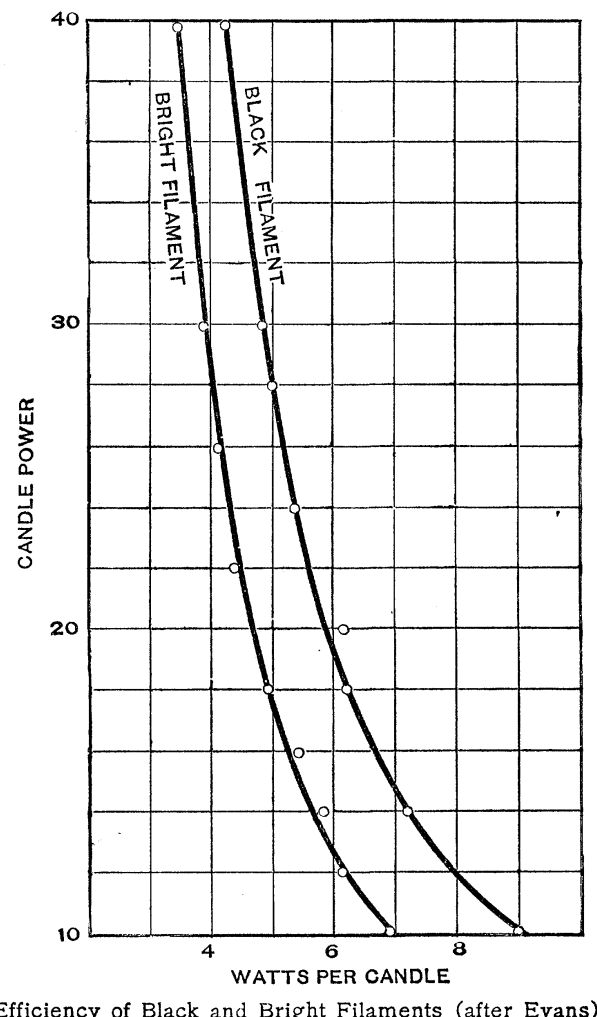

Efficiency of Black and Bright Filaments (after Evans). Fig. 1.

in the usual manner and securing a good vacuum, after which it was removed from the lamp and was flashed in hydro-carbon vapor. After exhaustion it was again tested, measurements showing marked increase in efficiency; then it was removed from the bulb for a second time and flashed in coal gas, by which process a new surface of the color of lampblack was obtained. Having been remounted in this final condition and thoroughly exhausted for the third time, another characteristic curve was obtained. This curve was found to coincide quite closely with that of the original untreated filament. These three curves are given in Fig. 2. 
[VoL. II.

Mr. Evans' experiments seem to leave no question as to the fact that the bright surface obtained by flashing in hydro-carbon vapor possesses properties which fit it peculiarly for the production of light. Evans noted the fact that the lamp bulbs containing the black filaments were much hotter than those which surrounded filaments with a silver-gray surface, and he remarks: "I have little

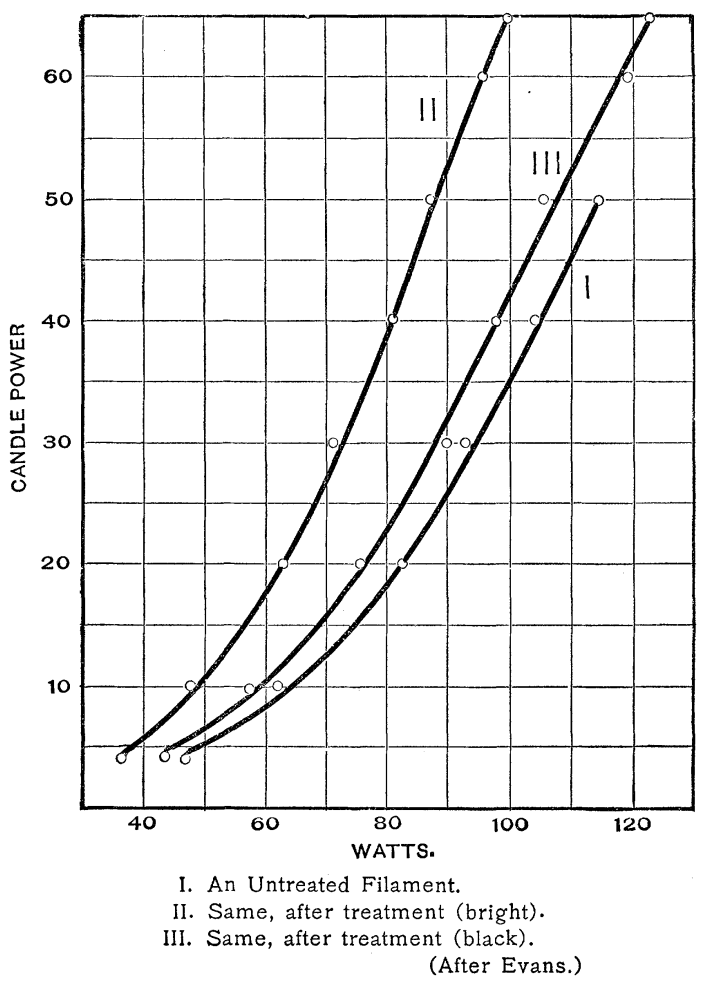

Fig. 2.

doubt that the loss of efficiency when black was due to the energy supplied being radiated in large quantities as heat waves from the blackened surfaces, which these surfaces when bright would not emit."

That the total radiating power of carbon in the form of lampblack is very much greater than that of the silver-gray graphitic form obtained by flashing in hydro-carbons has been shown by 
H. S. Weber in a paper read before the Electrical Congress in Frankfort in I89I. ${ }^{1}$ Weber, who tested thirty-three varieties of glow-lamp filaments, found for the black carbon a coefficient of total emission lying between 0.0000169 and 0.0000174 , and for treated filaments with bright surface, coefficients lying between 0.0000127 and 0.0000132 .

During the winter of I89I-92, Mr. John C. Shedd ${ }^{2}$ made a large number of comparisons of commercial lamps with treated and untreated filaments, for the purpose of further testing the conclusions reached by Evans. His method consisted in studying the visible spectrum of such lamps by means of the horizontalslit photometer. The lamps were maintained for this purpose at various degrees of incandescence.

Mr. Shedd's results were in the main confirmatory of the higher efficiency of bright carbons, but they indicate clearly that the efficiency of the incandescent lamp is dependent upon other factors than the character and radiating power of the surface of the filament. He found, for example, that the vacuum especially has much to do with the relationship between the energy developed in the lamp and the candle-power.

His comparisons between glow-lamps, at different stages of incandescence, and the gas-flame, bring out two facts which are of interest in the comparative study of treated and untreated filaments.

(I) Spectro-photometric measurements with lamps of untreated filaments of vegetable fiber showed that the light was of the same color as that from gas (in the argand burner) when the lamp was being operated at an efficiency of 6.8 watts per candle. All efficiencies lower than this showed relatively higher intensities in the red, while all efficiencies above 6.8 showed a light which was bluer than that of the gas. The relative intensities of the various wave-lengths in the light emanating from such filaments were found to vary quite rapidly as the incandescence rose. Such a lamp, for which the ratio $\frac{\text { glow-lamp }}{\text { gas-flame }}$ for the region of the $\mathrm{D}$ line was unity, gave for wave-length $0.4 \mu$ about I.6.

1 Weber, Verhandlungen des Internationalen Elektrotechniker-Congresses zu Frankfurt am Main, r891, II., p. 49. See also Physical Review, Vol. II.

2 Thesis : in Library of Cornell University, 1892. 
(2) In the case of treated filaments with bright surface, on the other hand, equality with gas-light as regards whiteness was reached only at somewhat higher efficiencies, viz. between 4 and 6 watts per candle. The changes in the color of the light from such lamps appeared, moreover, to be much less marked than in the case of filaments with black surface. The variation in quality, indeed, was frequently scarcely noticeable when the lamp was brought up from 7 to 4 watts per candle. It would appear from Mr. Shedd's measurements that in the case of black filaments the increase in the intensity of short wave-lengths with temperature was much more rapid than in the case of the longer wave-lengths; whereas with bright filaments all the wave-lengths of the visible spectrum gained in intensity at very nearly the same rate.

II.

A study of the results obtained by Mr. Shedd made it evident to me that the influence of the vacuum of the glow-lamp was so great as to render all comparisons unsatisfactory between different lamps in which the pressure was an unknown factor. In the hope of over-

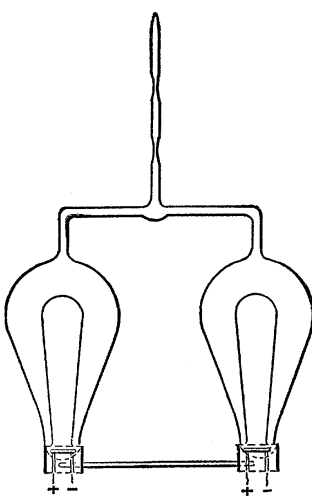

Fig. 3. coming this difficulty I had some lamps constructed, through the kindness of a friend engaged in the manufacture of glow-lamps, by means of which this difficulty could be obviated.

Two lamp filaments as nearly identical as possible were taken. These were brought to identity as regards resistance by the usual method of flashing in hydro-carbon vapor; one of them was then given a coat of black carbon by smoking. They were mounted in bulbs of the usual form, the two being connected by a glass tube as shown in Fig. 3 . The pair of lamps thus connected were placed upon a pump together, and were exhausted in the usual manner, after which they were sealed. These lamps could be brought to incandescence separately; but since there was permanent communication be- 
tween the interiors of the two bulbs, whatever changes in vacuum occurred in the one would be shared by the other lamp.

Upon measuring the candle-power, voltage, and current, in the case of these two lamps throughout a wide range of incandescence and platting the characteristic curves, it was found that the difference in efficiency as expressed by watts per candle was very great indeed. The efficiency of the smoked filament was extraordinarily low. Inspection of the results obtained made the cause of this difference obvious, the fact being that the mantle of carbon obtained by smoking was of extremely high electrical resistance. The result was that when the same current was sent through

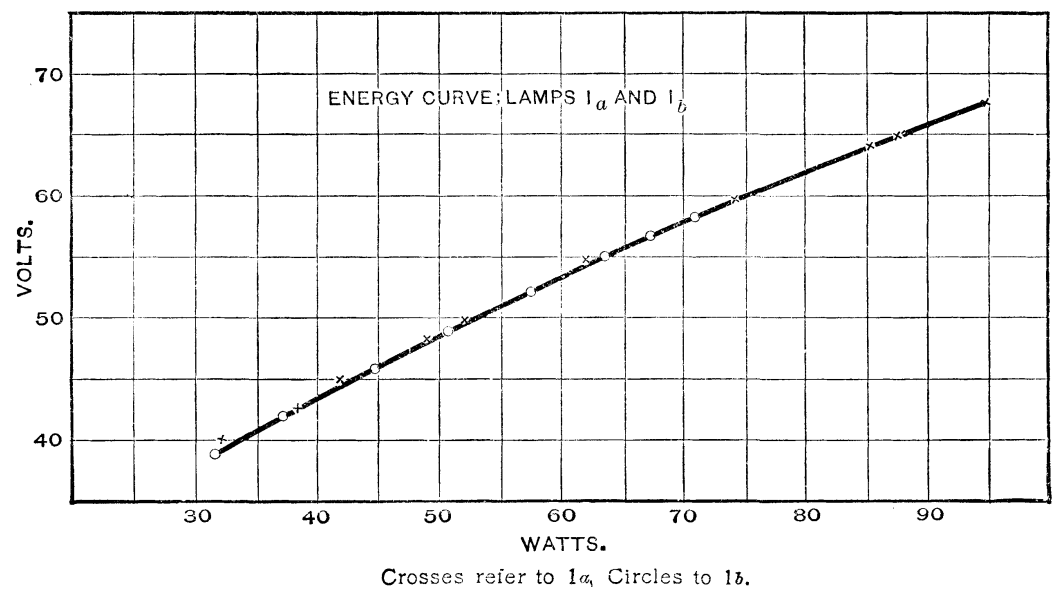

Fig. 4.

the two lamps, the total watts generated in each were identical (see Fig. 4); but since the radiating surface of the smoked filament was very largely increased, the temperature of the lamp was greatly lowered. The consequence was that the black lamp required a higher voltage and a correspondingly greater amount of energy to bring it to a given candle-power than did the bright filament, which was without the superficial non-conducting layer of carbon. It seems probable that something of the same kind may have occurred to vitiate the experiments made by $\mathrm{Mr}$. Evans, although, doubtless, the non-conducting film in the case of his lamps was much thinner than in the pair of lamps now 
under consideration. Although it was impracticable to compare these lamps with one another by the mere determination of the candle-power and the watts per candle, they afforded excellent material for the study of the laws of radiation of these two widely different carbon surfaces. I accordingly subjected them to detailed measurements as regards the distribution of energy in the infra-red of the spectrum through a very wide range of temperatures, making use, for this purpose, of a method nearly the same as that described by E. F. Nichols in the first volume of this Review. ${ }^{1}$ Indeed, in many of these measurements Mr. Nichols

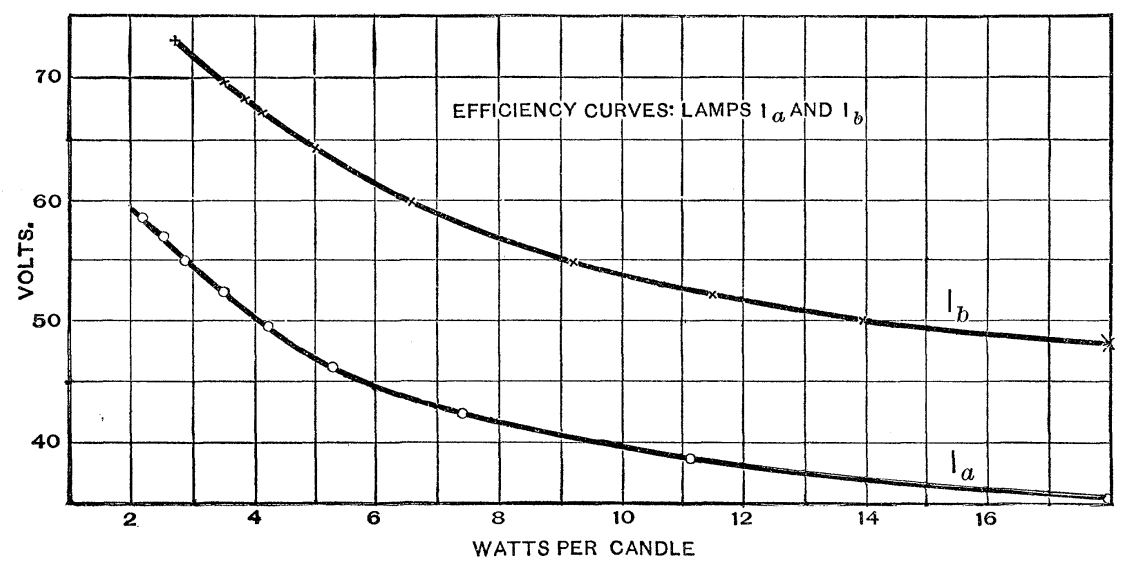

Fig. 5.

did me great service, bringing to bear upon what was in many respects an operation of unusual delicacy the skill attained by long practice in a similar research.

III.

The apparatus used in the study of the spectrum of these lamps was that described by Mr. Nichols in the paper just cited. It consists of a spectrometer, in place of the eyepiece of which is inserted a linear thermopile of antimony and bismuth, the edge of which had been filed down until only a very narrow strip was exposed to radiation. Dispersion was obtained by means of a

1 Nichols, Physical Review, Vol. I., p. I, I893. 
prism of carbon bi-sulphide contained between glass walls. This substance was selected because there is reason to believe that it obeys more closely than any other available material Cauchy's law for dispersion.

The use of the spectrometer with glass lenses, and of a prism the walls of which are of glass, in the study of the distribution of energy in the spectrum, is open to the serious objection that both glass and carbon bi-sulphide exert selective absorption upon the rays of light which pass through them. The only substitute for a prism and lenses would be a concave grating, or a plane grating used in connection with a concave mirror. The feebleness of the spectra produced by means of the grating offers in itself a serious hindrance to its use in bolometric work. The theory of the diffraction grating, as given by Rowland, is, moreover, conclusive as regards the unfitness of ruled gratings for the determination of energy in the spectrum, and it had been previously shown experimentally by Paschen that the exploration of the spectrum of incandescent lamps by means of the grating and bolometer led to results which were full of the most serious errors. No more striking verification of the theory can be given than the curves exhibited in Paschen's paper. So serious, indeed, are the vagaries of the diffraction grating in this respect that it would seem as though all work involving absolute measurements of the distribution of energy in the spectrum, in which diffraction has been made use of, must be discarded and the work done over by other methods.

As regards the fitness of the material used in the apparatus with which the experiments to be described were made, it may be noted that $\AA$ ngstrom has studied the absorption of carbon bi-sulphide in the infra-red and has found it to be transparent as far as wavelength $3.0 \mu$, beyond which lie two strong absorption bands. Since, however, my measurements do not extend beyond $3.0 \mu$, there seems to be every reason to assume that no serious errors will be introduced by the passage of the rays under investigation through this medium.

Ernest Nichols, in the article just cited, has studied the diathermancy of glass. His curve for the percentage of light trans- 
mitted by a plate of glass (see Physical Review, Vol. I, p. 8) indicates great uniformity in this material, up to the longest wavelengths to be considered. The diminution of light due to the interposition of the specimen of glass which he tested, is scarcely greater than the losses by reflection at the two faces of the plate, and while there is evidence of very slight decrease in the transmitting power as we pass from $2.0 \mu$ to $3.0 \mu$, the change cannot amount to more than one or two per cent. Under these circumstances, it seems quite safe to assume that no serious errors will result from selective absorption of the rays of the infra-red spectrum of glow-lamps, either by the glass of the lenses and the walls of the prism, or by the contents of the prism itself.

The most serious objection to the use of the bi-sulphide prism lies in the fact that the dispersion is very small for the longer wavelengths. The shortening of the spectrum in the infra-red is such that measurements beyond wave-lengths $3 \mu$ are of questionable value.

The choice of the thermopile, the width of the face of which was something more than half a millimeter, instead of a more strictly linear instrument such as the bolometer, is open to criticism. In point of fact, the thermopile showed itself to be so much more sensitive than any bolometer which Ernest Nichols and the writer were able to construct, that we were led to adopt it in spite of this objection. It seemed quite certain, moreover, that there was but little of interest to be found in the spectrum of glow-lamps beyond the regions which it was possible to explore with the thermopile, so that it did not seem worth while to expend a great deal of time in the construction of a bolometer.

Our experience appears to differ from that of others who have worked in this field; but it may not be without interest to state that we both tried bolometers constructed of the platinum crosshair wire, used by Snow in his exploration of the bright line spectra of the alkalies, - an investigation which would seem to demand the very highest delicacy; also bolometric strips of iron, nickel, aluminium, etc. We were not able within the time at our disposal to construct a bolometer, the sensitiveness of which for the purposes of our measurements was greater than one-twentieth of that of the linear thermopile. 
The galvanometer used in these studies was the one briefly described by Ernest Nichols in his article already cited. It was built in the instrument shop of the department by F. C. Fowler, but the moving parts were made by Mr. Nichols, to whom also I owe the very careful study of the bi-sulphide prism.

IV.

Mr. Nichols, in his paper, has described briefly the calibration of the bi-sulphide prism. Since, in work of the kind under consideration, the accuracy of this calibration is of the utmost importance for the determination of wave-lengths in the infra-red, it may be well to give some additional details. The containing vessel of the prism consisted of a block of cast iron bored through so as to give a cylindrical opening about $4 \mathrm{~cm}$. in diameter. The glass faces of the prism were cemented over this opening, forming an angle of almost exactly $60^{\circ}$. Since the refractive index of carbon bi-sulphide changes greatly with the temperature, it was necessary to have an accurate knowledge of the temperature of the contents of the prism at the time when each measurement was made. The method finally adopted for this purpose was as follows :-

At the back of the prism a small pocket was constructed, one side of which was formed by the iron wall of the prism itself. Within this a delicate thermometer was inserted, the bulb of which was surrounded by water.

The dark room, within which the spectrometer was mounted, was an inside room of the laboratory, containing only one opening, that, viz., through which the rays from the incandescent lamp which it was our purpose to study reached the collimator lens of the spectrometer. The temperature changes in this room were very slow, and a comparison of the readings of the thermometer with those of a similar instrument, the bulb of which was placed within the liquid of the prism itself, showed that the difference of temperature within and without, through the very slight range to which both would be subjected, was negligible. Having satisfied ourselves that the indications of the thermometer in the water 
pocket at the back of the prism might be taken, the other thermometer was withdrawn and the prism was sealed up. Readings of the remaining thermometer were made before and after each set of readings.

The prism was standardized for a temperature of $23.5^{\circ} \mathrm{C}$., a reading which represented very nearly the mean temperature of the room, and all observations were reduced to this temperature. The entire range to which the prism was subjected in the course of the measurements was about $3^{\circ}$. The indices of refraction of the prism were determined by Mr. Nichols with great care for temperatures lying within the above-mentioned range, the wave-lengths selected for this purpose being those of the $\mathrm{C}$ and $\mathrm{F}$ lines of Fraunhofer. The results of this calibration, which are given in Table I. of Mr. Nichols' paper, are in close agreement with similar determinations made by Wüllner.

The method of calibration consisted in determining with all possible accuracy the Cauchy equation of the prism from the indices of refraction at the standard temperature for wave-lengths corresponding to the lines $\mathrm{A}, \mathrm{B}, \mathrm{C}$, and $b$ of Fraunhofer. By means of the equation thus obtained a curve was platted extending to the wave-lengths in the infra-red which we wished to measure. This method of determining the longer waves is less satisfactory in some respects than that made use of by Mouton and afterwards by Rubens, but it was believed that the errors thus introduced would not be important in comparison with those which result from other sources.

\section{V.}

Briefly stated, the method of experimenting was as follows :-

The thermopile already described was placed in closed circuit with the galvanometer, the latter instrument having been sensitized to a degree found by previous trials to suffice for the exploration of the region to be tested. The spectrometer was then set to a circle reading corresponding, at normal temperature, to the wave-length in question. The thermometer was then read, the time noted, and the inner room was closed, not to be entered again until the measurements for that region of the spectrum had been completed. 
The thermal disturbances produced in the course of these preliminary adjustments lasted in uncontrollable intensity for about thirty minutes, after which time it became possible to bring the galvanometer needle to a position such as to render the scale visible to an observer at the telescope. The drift, still very rapid, would then diminish in the course of ten minutes more to a state of comparative repose, such that readings for the ballistic throw could be obtained. The next step was to close the lamp circuit and to read volts and amperes. The galvanometer was then brought to the proper part of the scale, and preliminary calibrating throws were taken. For the purpose of calibration a subsidiary coil was used. This coil was mounted permanently about twenty centimeters behind the needles. It could be thrown into shunt circuit with a compensated resistance through which flowed a very steady current from a storage battery. The current was measured from time to time by means of an accurate mil-ammeter. The swing due to the closing of the circuit of the subsidiary coil gave the relative sensitiveness of the galvanometer. Such calibrations were made before and after every reading of the thermopile throws, and thus all the determinations were rendered reducible to a common scale, although the figure of merit of the galvanometer varied greatly in the course of the experiments.

After the completion of the preliminary calibration, the radiation measurements were begun, sets of five throws being taken for each condition of the lamp, which was changed stepwise between each set until the entire range to be covered had been included.

When all the readings to be made for the region of the. spectrum to which the thermopile was exposed had been completed, the inner room was entered, the thermometer was read, and the time noted. The spectroscope was then set to a new wave-length, and after thermal equilibrium had again established itself, the operations above described were repeated. In this way the entire infrared spectrum between $0.8 \mu$ and $3.0 \mu$ was explored.

The data thus obtained were reduced in the following manner:-

(I) All deflections were brought to a common scale by reference to the continually repeated calibration throws.

(2) Wave-lengths were determined by correcting the values cor- 
responding to the circle readings of the spectroscope for temperature. These corrections were obtained graphically from calibration curves platted to a large scale.

(3) The deflections were corrected for the width of the face of the thermopile. This was a most important correction, since, owing to the fact that the spectrum was prismatic instead of being normal, the surface of the pile received radiation from a larger and larger number of waves as the wave-lengths increased.

To be comparable one with another, in different parts of the spectrum, the deflections should be those obtained by exposure of

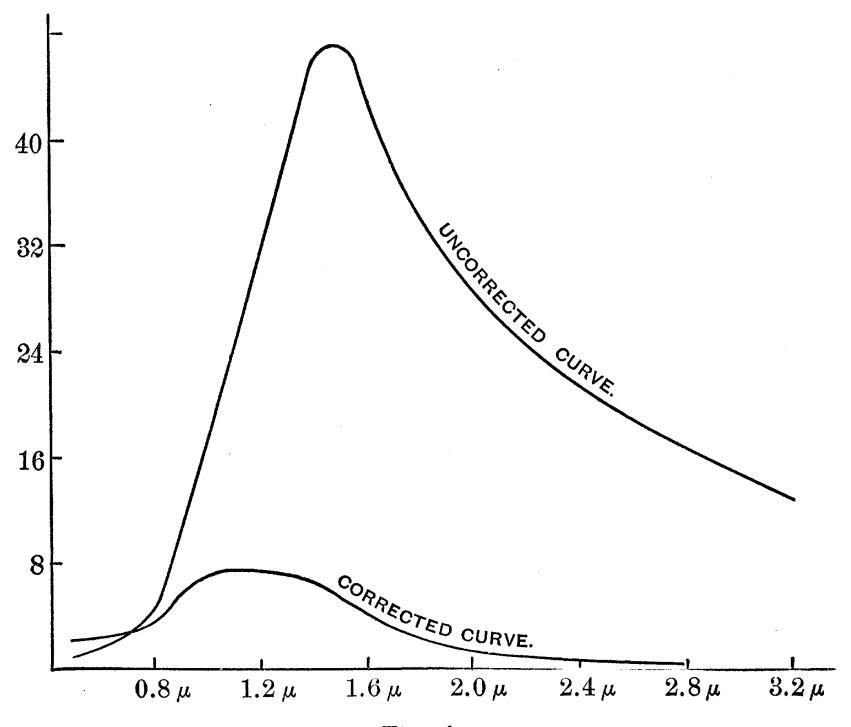

Fig. 6.

a surface varying in width with its position, in such a manner as always to receive radiation from a region of unit breadth, measured in wave-lengths. This correction it was possible to apply with satisfactory approximation up to wave-length $3 \mu$. How important this correction was will appear from Fig. 6, in which a corrected and uncorrected curve are platted to a common scale. In this diagram the width of the thermopile is taken as normal for the region of the D line.

The two lamps described in the second section of this paper 
were measured throughout a range of temperatures from the red heat upwards to a condition of incandescence beyond which they could not be carried without rapid deterioration. The corrected results are given in the following tables :-

TABLE I.

SPECTRUM OF GLOW-LAMP $\mathbf{I}_{b}$ (BLACK FILAMENT).

\begin{tabular}{|c|c|c|c|c|c|c|}
\hline \multirow{2}{*}{$\begin{array}{l}\text { Wave } \\
\text { lengths. }\end{array}$} & \multicolumn{6}{|c|}{ Intensities at } \\
\hline & 35 watts. & 45 watts. & 55 watts. & 65 watts. & 75 watts. & 85 watts. \\
\hline $0.8 \mu$ & 0.360 & 0.744 & 1.140 & 1.490 & 1.820 & 2.220 \\
\hline 1.0 & 0.859 & 1.450 & 2.050 & 2.700 & 3.410 & 4.180 \\
\hline 1.2 & 1.560 & 2.350 & 3.170 & 4.040 & 5.010 & 6.090 \\
\hline 1.4 & 2.280 & 3.150 & 3.970 & 4.730 & 5.4 .60 & 6.160 \\
\hline 1.6 & 1.560 & 2.050 & 2.590 & 3.050 & 3.490 & 3.830 \\
\hline 1.8 & 0.859 & 1.140 & 1.360 & 1.630 & 1.860 & 2.080 \\
\hline 2.0 & 0.490 & 0.656 & 0.793 & 0.923 & 1.050 & 1.160 \\
\hline 2.4 & 0.148 & 0.195 & 0.240 & 0.284 & 0.325 & 0.362 \\
\hline 2.8 & 0.0465 & 0.0613 & 0.0768 & 0.0910 & 0.106 & 0.194 \\
\hline
\end{tabular}

TABLE II.

SPECTRUM OF GLOW-LAMP $\mathbf{I}_{a}$ (BRIGHT FILAMENT).

\begin{tabular}{|c|c|c|c|c|c|c|c|c|c|}
\hline \multirow{2}{*}{ 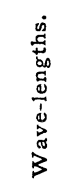 } & \multicolumn{9}{|c|}{ Intensities at } \\
\hline & 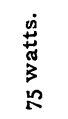 & 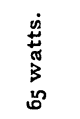 & 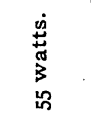 & 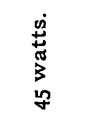 & 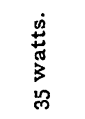 & 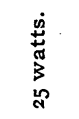 & $\begin{array}{l}\dot{0} \\
\stackrel{0}{n} \\
3 \\
3 \\
0\end{array}$ & $\begin{array}{l}\dot{0} \\
\text { 芴 } \\
3 \\
0 \\
0\end{array}$ & 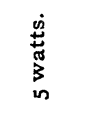 \\
\hline $0.7 \mu$ & 2.22 & 1.66 & 1.08 & 0.626 & 0.240 & 0.107 & - & - & - \\
\hline $0.8 \mu$ & 3.30 & 2.62 & 1.90 & 1.260 & 0.744 & 0.464 & 0.248 & 0.224 & - \\
\hline 0.9 & 5.45 & 4.22 & 3.13 & 2.270 & 1.480 & 0.900 & 0.372 & 0.306 & - \\
\hline 1.0 & 6.43 & 5.16 & 3.17 & 2.970 & 2.040 & 1.300 & 0.461 & 0.312 & 0.167 \\
\hline 1.2 & 6.84 & 5.84 & 4.75 & 3.790 & 2.790 & 1.74 & 0.732 & 0.372 & 0.313 \\
\hline 1.4 & 6.27 & 5.50 & 4.72 & 3.880 & 3.050 & 2.06 & 0.799 & 0.599 & 0.419 \\
\hline 1.6 & 4.40 & 3.86 & 3.27 & 2.680 & 2.030 & 1.33 & 0.572 & 0.418 & 0.257 \\
\hline 1.8 & 2.20 & 2.02 & 1.78 & 1.480 & - & 0.813 & 0.361 & 0.281 & 0.179 \\
\hline 2.0 & 1.31 & 1.20 & 1.07 & 0.908 & - & 0.523 & 0.255 & 0.199 & 0.115 \\
\hline 2.4 & 0.64 & 0.527 & 0.467 & 0.400 & 0.333 & 0.258 & 0.147 & 0.125 & 0.118 \\
\hline 2.8 & 0.28 & 0.259 & 0.233 & 0.204 & 0.169 & 0.133 & 0.077 & 0.0633 & 0.0469 \\
\hline
\end{tabular}


Of these two sets of measurements, those upon the lamp with the bright filament were the more complete, being carried down to temperatures much below the red heat. The results may be treated graphically in either of two ways :-

(I) By the construction of curves with intensities as ordinates

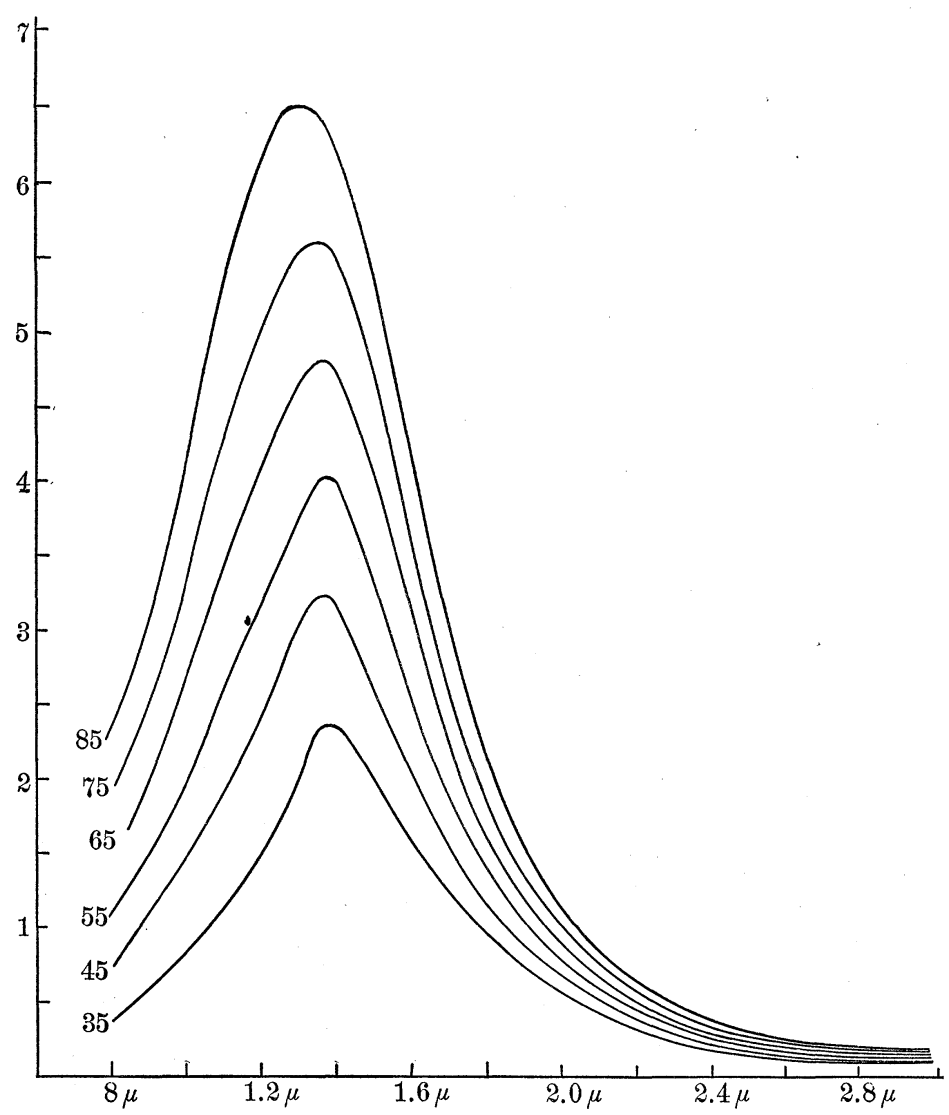

Fig. 7.

and electrical activity expressed in watts as abscissas, each curve representing a separate wave-length.

(2) By platting intensities as ordinates, and wave-lengths as abscissas.

Curves obtained by the former method show the rise in intensity 
for each wave-length with increase in the energy expended in the lamp. These curves are very similar in form to those for the radiation of platinum as a function of the temperature, as measured by the writer ${ }^{1}$ and also by Violle.

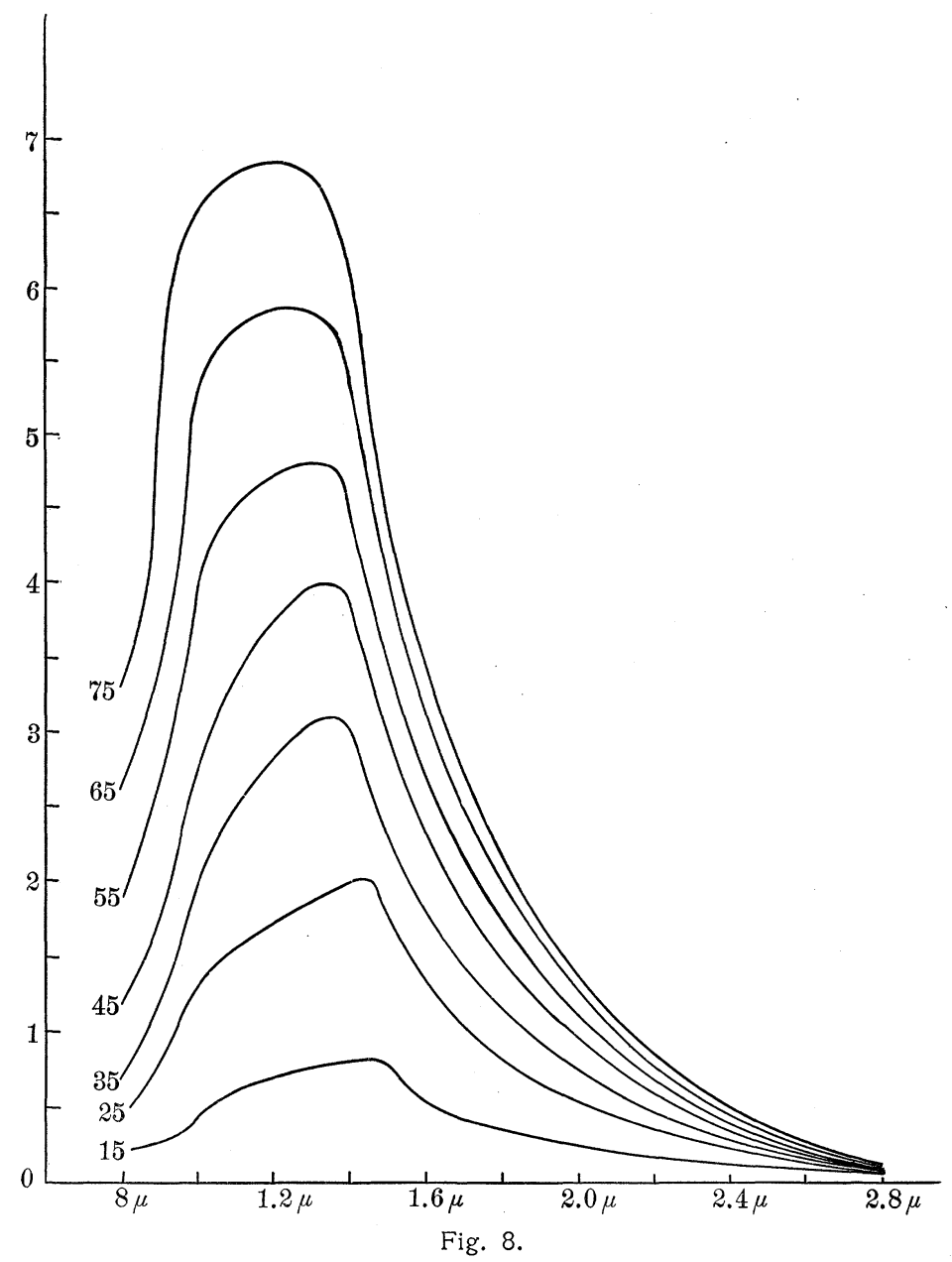

The curves of the second type are shown in Fig. 7, which shows the distribution of energy in the spectrum of the lamp with lampblack-coated filament $\left(\mathrm{I}_{b}\right)$, and in Fig. 8, which gives similar curves

1 Nichols, Ueber das von glühendem Platinum ausgestrahlte Licht. Göttingen, I879. 
for the lamp with bright filament $\left(\mathrm{I}_{a}\right) \cdot{ }^{1}$ It will be seen that the distribution is very different in the two cases, the maximum in the case of the latter being nearer the visible spectrum. Were both sets of curves extended to the shorter wave-lengths, it would unquestionably be found that the area of the portions lying within the range of the luminous rays is larger in the case of bright filaments, a result which would afford a complete explanation of the superiority of such filaments in the production of light, as shown by Evans in the experiments already described.

Similar measurements to the above were made upon a commercial lamp with untreated filament bamboo. The lamp in question is the one used as a reference light in the experiments of E. F. Nichols upon absorption in the infra-red. ${ }^{2}$ It will be seen, by reference to his curves, that the distribution in the spectrum of this lamp was in every respect similar to that in the spectrum of lamp $I_{b}$.

The complete investigation of the problem with which this present paper deals would involve the direct measurement of the temperatures of the radiating surface. In such an investigation, to which the experiments here described are preliminary, the writer is now engaged. The results are to be given in a subsequent article.

1 The only measurements in any way comparable with these, so far as the writer is aware, are those of Abney and Festing. Their curves are, however, platted with scale readings instead of wave-lengths as abscissas, so that it is difficult to make any exact comparison.

2 E. F. Nichols, l.c. 